\title{
Microwave-assisted heterocyclic synthesis ${ }^{\ddagger}$
}

\author{
Alan R. Katritzky* and Sandeep K. Singh \\ Center for Heterocyclic Compounds, Department of Chemistry, \\ University of Florida, Gainesville, FL 32611-7200 \\ E-mail: Katritzky@chem.ufl.edu
}

\section{Dedicated with all good wishes to Boris Trofimov on his $65^{\text {th }}$ anniversary}

(received 03 June 03; accepted 14 July 03; published on the web 22 July 03)

\begin{abstract}
Recent applications of microwave technology in well-known cyclization reactions for heterocyclic ring formation and in other important reactions such as nucleophilic substitution, hetero-Diels-Alder reactions, 1,3-dipolar cycloaddition etc. have been discussed. A comparison with the conventional methods demonstrates the advantages of microwaves in synthetic heterocyclic chemistry.
\end{abstract}

Keywords: Heterocycles, conventional heating, microwaves, single-mode technology

\section{Contents}

Introduction

1. Applications of microwaves in heterocyclic ring formation

1.1. Five-membered heterocyclic rings

1.1.1. Pyrroles

1.1.2. Pyrazoles

1.1.3. Imidazoles

1.1.4. Oxazolines

1.1.5. Triazoles and tetrazoles

1.1.6. Oxadiazoles

1.1.7. Isoxazolines and pyrazolines

1.2. Benzo-derivatives of Five-membered rings

1.2.1. Benz-imidazoles, -oxazoles, and -thiazoles

1.2.2. Indoles

1.2.3. $\gamma$-Carbolines

1.3. Six-membered rings

1.3.1. Dihydropyridines

1.3.2. Dihydropyridopyrimidinones 
1.3.3. Dihydropyrimidines

1.3.4. Tetrazines

1.4. Polycyclic six-membered rings

1.4.1. Quinolines

1.4.2. Pyrimido[1,2-a]pyrimidines

2. Nucleophilic substitutions

2.1. Heterocyclic C-alkylations

2.2. Heterocyclic N-alkylations

2.3. Selective-alkylation

2.4. Transition metal cross-coupling

3. Hetero-Diels-Alder reactions

3.1. Intramolecular reactions

3.2. Intermolecular reactions

4. 1,3-Dipolar cycloaddition reactions

4.1. Synthesis of C-carbamoyl-1,2,3-triazoles

4.2. Synthesis of substituted mono-triazoles

4.3. Synthesis of substituted bis-triazoles

5. N-chlorination of amides

Acknowledgments

References

\section{Introduction}

Microwave heating has emerged as a powerful technique to promote a variety of chemical reactions. ${ }^{1}$ Microwave reactions under solvent-free conditions are attractive in offering reduced pollution and offer low cost together with simplicity in processing and handling. ${ }^{2}$ The recent introduction of single-mode technology ${ }^{3}$ assures safe and reproducible experimental procedures and microwave synthesis has gained acceptance and popularity among the synthetic chemist community. The growing number of publications in microwave-assisted synthesis includes virtually all types of chemical reactions such as additions, cycloadditions, substitutions, eliminations, fragmentations etc. ${ }^{3}$

In the present short review, we are trying to highlight some of the applications of microwave methodology in heterocyclic chemistry. The graphic enhancements in the speed of reactions and in yields are striking. Undoubtedly, microwaves are going to be highly important in future synthesis of heterocycles. Bearing in mind that most biologically active compounds are heterocyclic and the importance in combinatorial chemistry to identify leads and to optimize structures, we believe that the number of applications of microwaves will only increase in the future. The present review is organized to emphasize some of the most important areas that have so far been identified. 


\section{Applications of microwaves in heterocyclic ring formation 1.1. Five-membered heterocyclic rings}

\subsubsection{Pyrroles}

The classical Paal-Knorr cyclization of 1,4-diketones to give pyrroles is dramatically speededup under microwave irradiation and high yields are obtained as shown in Scheme $1{ }^{4}$

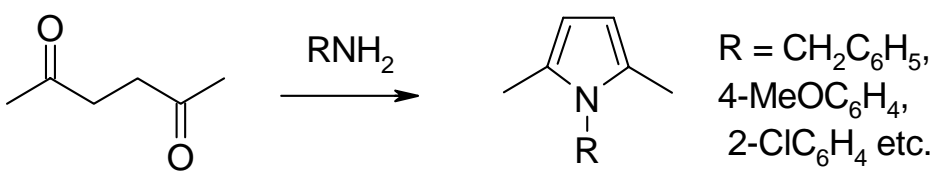

$75-90 \%$

MW, 100-200 W, 0.5-2.0 min., solvent-free

Microwave: 2 min.

Conventional: Lewis acid activation, $12 \mathrm{~h}$.

\section{Scheme 1}

\subsubsection{Pyrazoles}

Another recent application of microwaves in cyclization is the preparation of pyrazoles from hydrazones using the Vilsmeier cyclization method by treatment with $\mathrm{POCl}_{3}$ and $\mathrm{DMF}^{5}$ As shown in Scheme 2, once again the reaction is speeded-up by factors of several 100-fold.

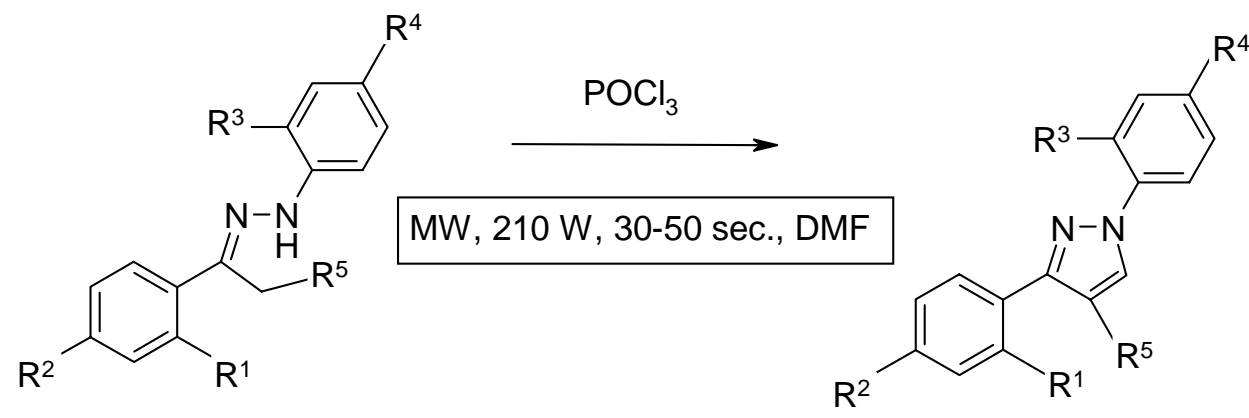

$$
\begin{array}{ll}
\text { Microwave: } 35-50 \text { sec., 45-78\% } & \mathrm{R}^{1}=\mathrm{H}, \mathrm{OH} ; \mathrm{R}^{2}=\mathrm{H}, \mathrm{CH}_{3} ; \\
\text { Conventional: } 4-5 \mathrm{~h}, 41-76 \% & \mathrm{R}^{3}=\mathrm{H}, \mathrm{NO}_{2} ; \mathrm{R}^{4}=\mathrm{NO}_{2} ; \\
& \mathrm{R}^{5}=\mathrm{CH}_{3}, \mathrm{C}_{2} \mathrm{H}_{5}
\end{array}
$$

\section{Scheme 2}

\subsubsection{Imidazoles}

An important classical preparation of imidazoles is from an $\alpha$-diketone, an aldehyde and ammonia. Here again, excellent yields can be obtained in reaction times of a few minutes as shown in Scheme $3 .^{6}$ 


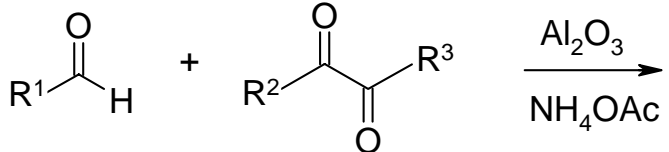

MW, $130 \mathrm{~W}, 10$ min., solvent-free<smiles>[R]c1nc([R])c([R])[nH]1</smiles>

$75-85 \%$
Microwave: $10 \mathrm{~min}$.

Conventional: $4 \mathrm{~h}, \mathrm{AcOH}$ reflux
$\mathrm{R}^{1}=\mathrm{C}_{6} \mathrm{H}_{5}, 4-\mathrm{ClC}_{6} \mathrm{H}_{4}$,

2-thiophenyl etc.

$\mathrm{R}^{2}=\mathrm{R}^{3}=\mathrm{C}_{6} \mathrm{H}_{5}, 4-\mathrm{MeC}_{6} \mathrm{H}_{4}$

\section{Scheme 3}

\subsubsection{Oxazolines}

The example of Scheme 4, the preparation of oxazolines shows that partially saturated fivemembered rings can also be prepared advantageously using microwaves. ${ }^{7}$

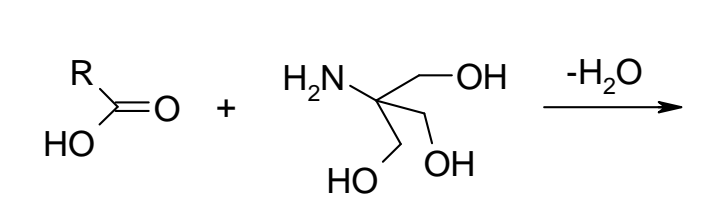

$\mathrm{MW}, 850 \mathrm{~W}, 200^{\circ} \mathrm{C}, 5 \mathrm{~min}$., solvent-free

Microwave: 5 min.

Conventional: 15-16 h<smiles>[R]C(=O)NC(CO)(CO)CO</smiles>

\section{Scheme 4}

$\mathrm{R}=$ 2-furyl, phenyl, heptadecenyl
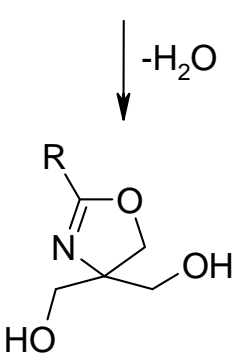

$80-95 \%$

\subsubsection{Triazoles and Tetrazoles}

Schemes 5 and 6 continue the overview of five-membered rings with illustrations of the advantageous preparation of 1,2,4-triazoles (Scheme 5) ${ }^{8}$ and tetrazoles (Scheme 6) ${ }^{9}$ using microwaves. Notice that in Scheme 6 the starting aryl cyanides are also made by a Pd-catalyzed but microwave-enhanced replacement of aryl bromides using zinc cyanide. 


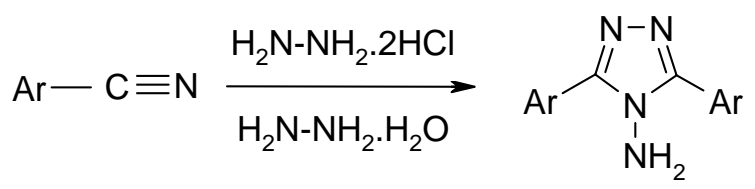

MW, $60 \mathrm{~W}, 130^{\circ} \mathrm{C}, 4-10 \mathrm{~min}$., ethylene glycol

Microwave: 10 min., $130^{\circ} \mathrm{C}, 63-96 \%$ Conventional: $60 \mathrm{~min} ., 130{ }^{\circ} \mathrm{C}, 45-60 \%$

$$
\begin{aligned}
& \mathrm{Ar}=\mathrm{C}_{6} \mathrm{H}_{5}, 4-\mathrm{CH}_{3} \mathrm{C}_{6} \mathrm{H}_{4}, \\
& \text { 4- } \mathrm{NH}_{2} \mathrm{C}_{6} \mathrm{H}_{4}, 4-\mathrm{OHC}_{6} \mathrm{H}_{4}, \\
& \text { 4- } \mathrm{CH}_{3} \mathrm{OC}_{6} \mathrm{H}_{4} \text { etc. }
\end{aligned}
$$

\section{Scheme 5}

\section{Scheme 6}<smiles>[R]c1ccc(Br)cc1</smiles>

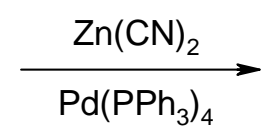

$\mathrm{MW}, 60 \mathrm{~W}, 175^{\circ} \mathrm{C}, 2 \mathrm{~min} ., \mathrm{DMF}$

Microwave: 2 min., 78-93\%

Conventional: 2-16 h, 71-97\%

MW, $20 \mathrm{~W}, 220^{\circ} \mathrm{C}, 10-25$ min., DMF

Microwave: 10-25 min., 36-96\%

Conventional: 3-96 h, 35-97\%<smiles>[R]c1ccc(C#N)cc1</smiles>

$\mathrm{NaN}_{3}$ $\mathrm{NH}_{4} \mathrm{Cl}$

$\checkmark$<smiles>[R]c1ccc(-c2nnn[nH]2)cc1</smiles>

$\mathrm{R}=\mathrm{OCH}_{3}, \mathrm{NO}_{2}, \mathrm{CH}_{3}$ etc.

\subsubsection{Oxadiazoles}

The dehydration of unsymmetrical diacylhydrazines (themselves prepared by a conventional Mitsunobu reaction) using Burgess's reagent is shown in Scheme 7 to give 1,3,4-oxadiazoles rapidly under microwave irradiation. ${ }^{3}$

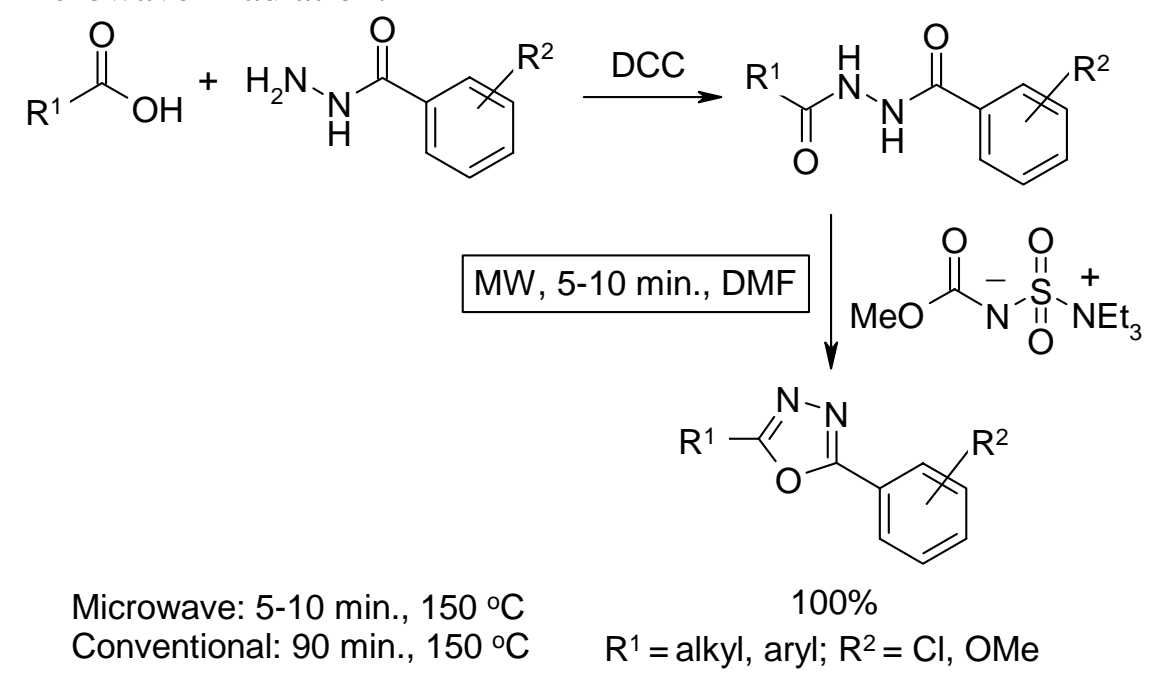

\section{Scheme 7}




\subsubsection{Isoxazolines and pyrazolines}

The acceleration of 1,3-dipolar cycloaddition reactions to give isoxazolines and pyrazolines by the addition of activated olefins to nitrile oxides or nitrile imides, respectively, is illustrated in Scheme 8; the resulting compounds are obtained in far high yield than under conventional conditions. ${ }^{10}$

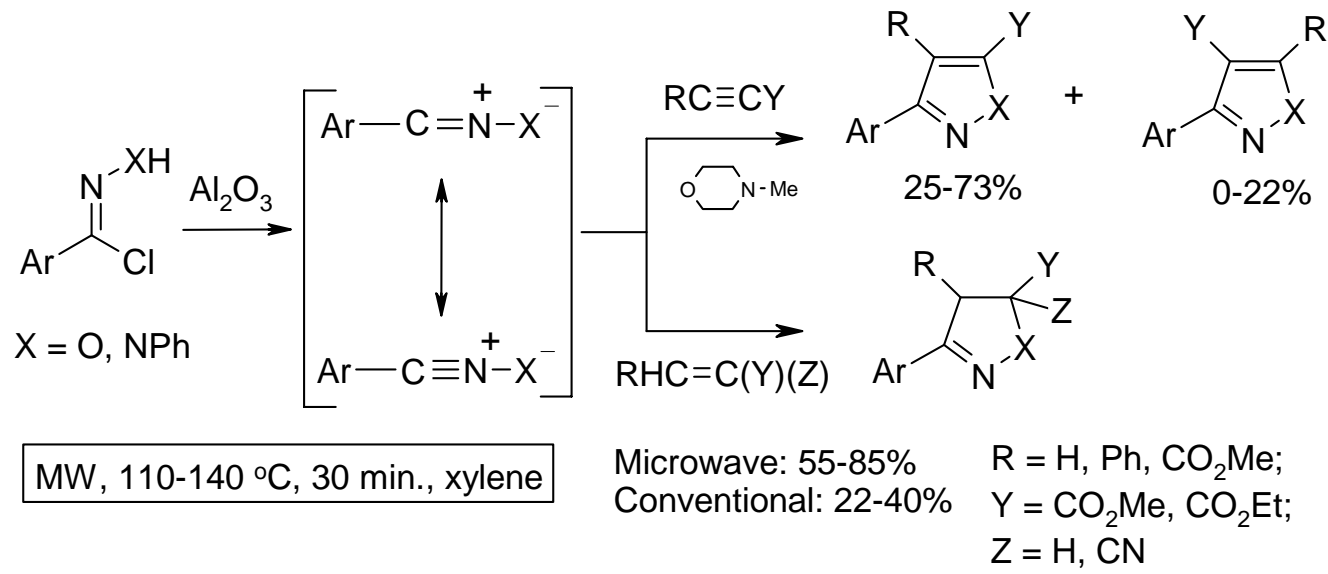

\section{Scheme 8}

\subsection{Benzo-derivatives of five-membered rings}

\subsubsection{Benz-imidazoles, -oxazoles, and -thiazoles}

Ring closure reactions of appropriate $o$-substituted anilines to give benzimidazoles, benzoxazoles, and benzthiazoles takes place much faster and in significantly high yield under microwave conditions $^{11 \mathrm{a}}$ than conventionally ${ }^{11 \mathrm{~b}}$ as shown in Scheme 9.

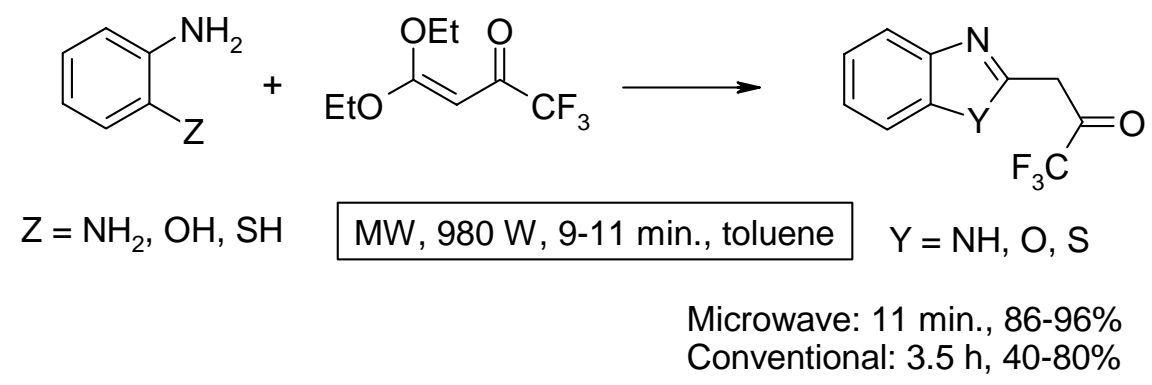

\section{Scheme 9}

\subsubsection{Indoles}

The classical Fischer-indole synthesis from an aryl hydrazine and a ketone is speeded-up by several 100-fold as documented in Scheme $10 .^{12}$ 


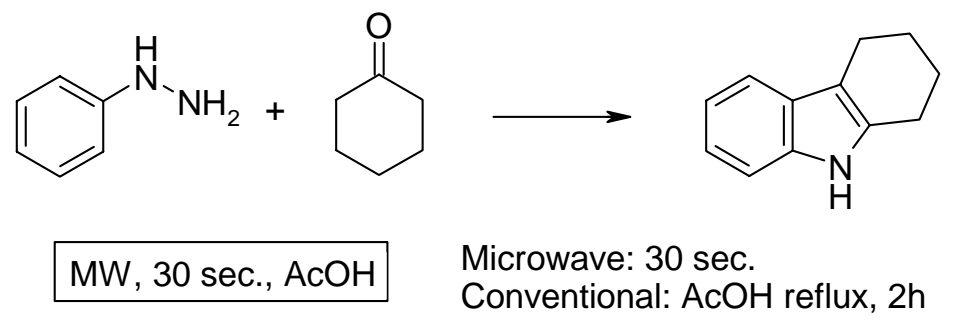

\section{Scheme 10}

\subsection{3. $\gamma$-Carbolines}

The Graebe-Ullmann synthesis which converts 1-arylbenzotriazoles into carbazoles or their heterocyclic analogs is also accelerated under microwave conditions as shown in Scheme 11 where the 1-(4-pyridyl)benzotriazole is converted into a $\gamma$-carboline. ${ }^{13}$

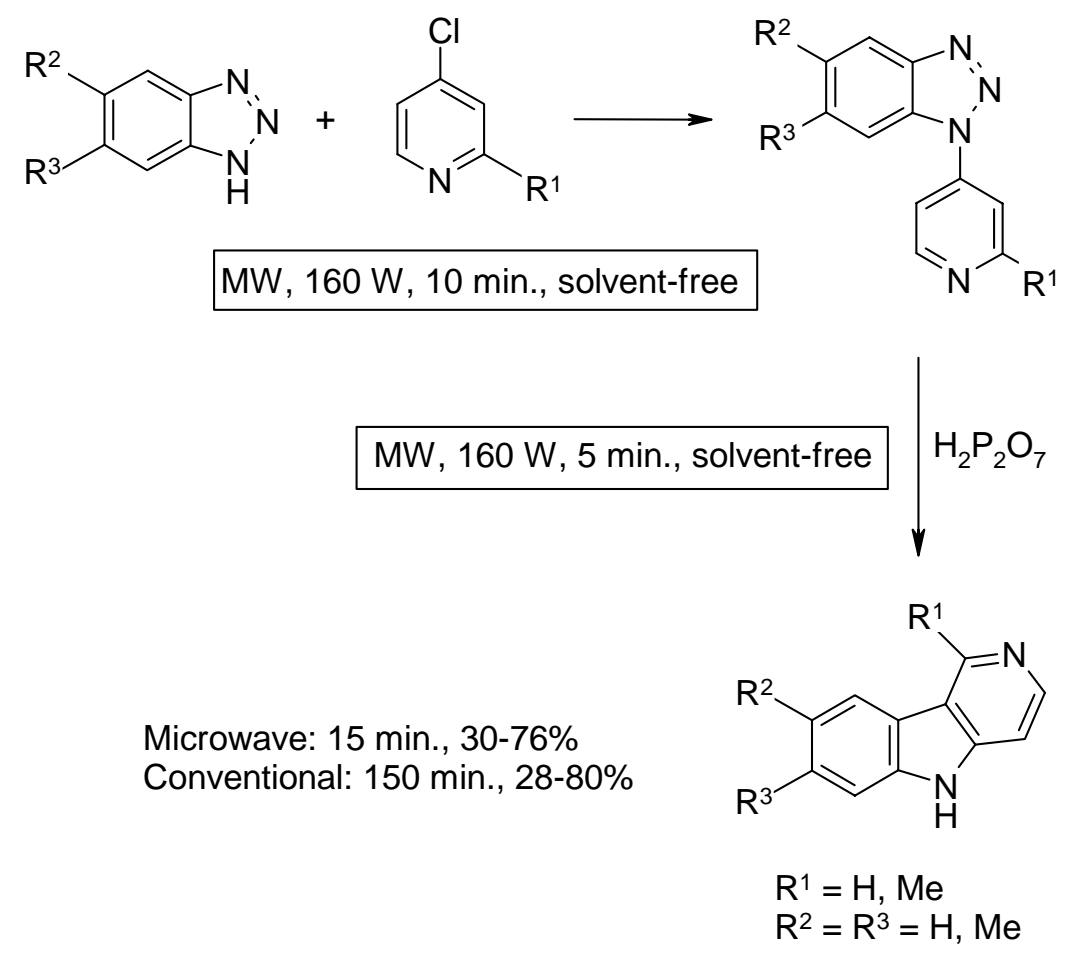

\section{Scheme 11}

\subsection{Six-membered rings}

\subsubsection{Dihydropyridines}

The Hantzsch dihydropyridine synthesis remains one of the most important routes to pyridine ring systems. Under conventional conditions long periods of heating are required and yields are poor to moderate. Microwaves dramatically reduce the heating times and also significantly increase the yields as shown in Scheme 12. ${ }^{14}$ 


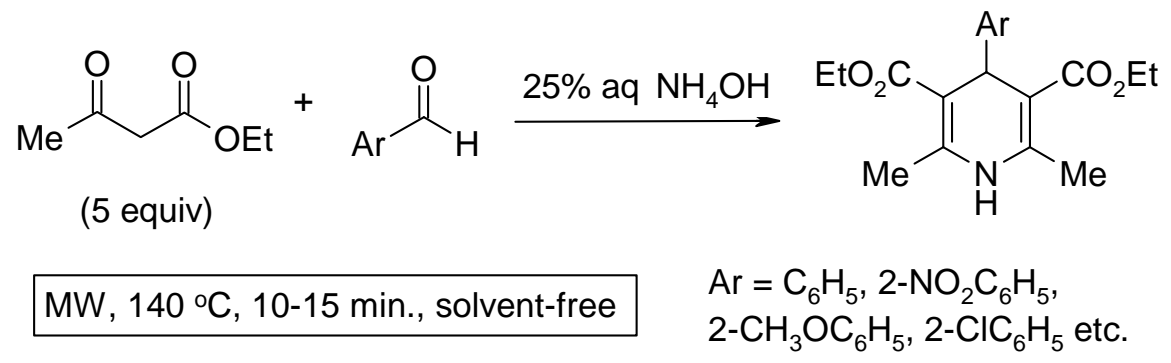

Microwave: $10-15$ min., $51-92 \%$

Conventional: 12 h, $15-61 \%$

\section{Scheme 12}

\subsubsection{Dihydropyridopyrimidinones}

Dihydropyridopyrimidinones have been produced by ring annulations of aminopyrimidinones. Once again the reaction time is dramatically reduced and yields are much better with the solventfree microwave conditions (Scheme 13). ${ }^{15}$

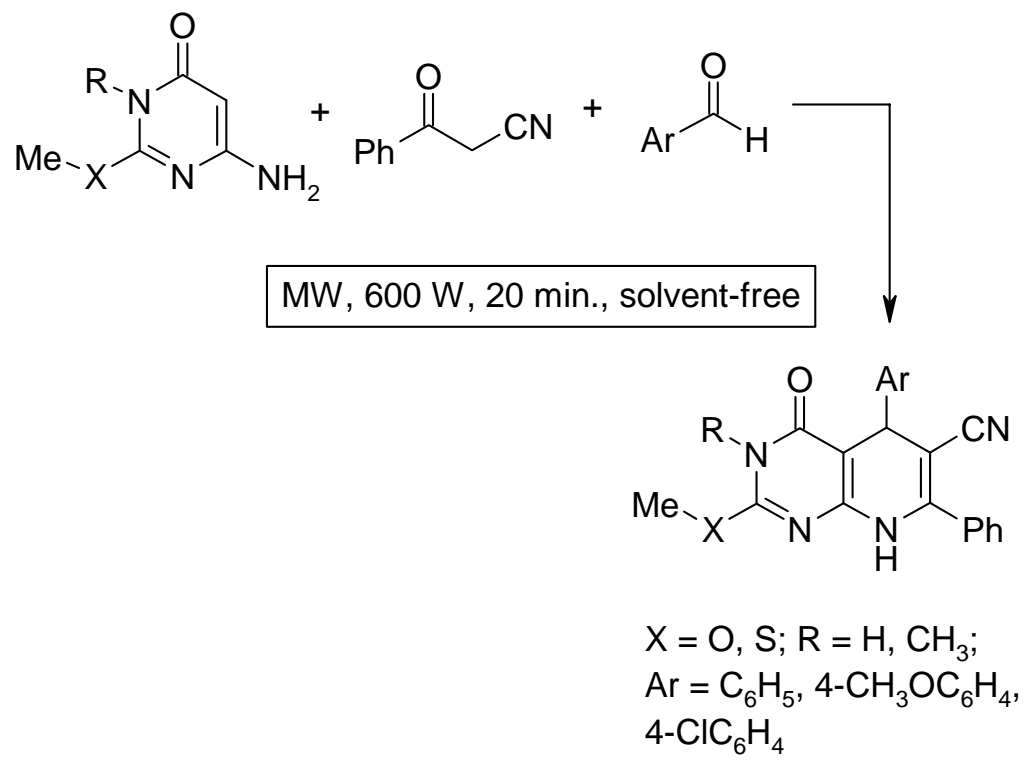

Microwave: $15-20$ min., $70-75 \%$

Conventional: EtOH reflux, 40-48 h, 21-25\%

\section{Scheme 13}

\subsubsection{Dihydropyrimidines}

The Biginelli reaction is important for the preparation of dihydropyrimidine derivatives and excellent results are found for reactions carried out with microwave enhancement (Scheme 14). ${ }^{3}$ 


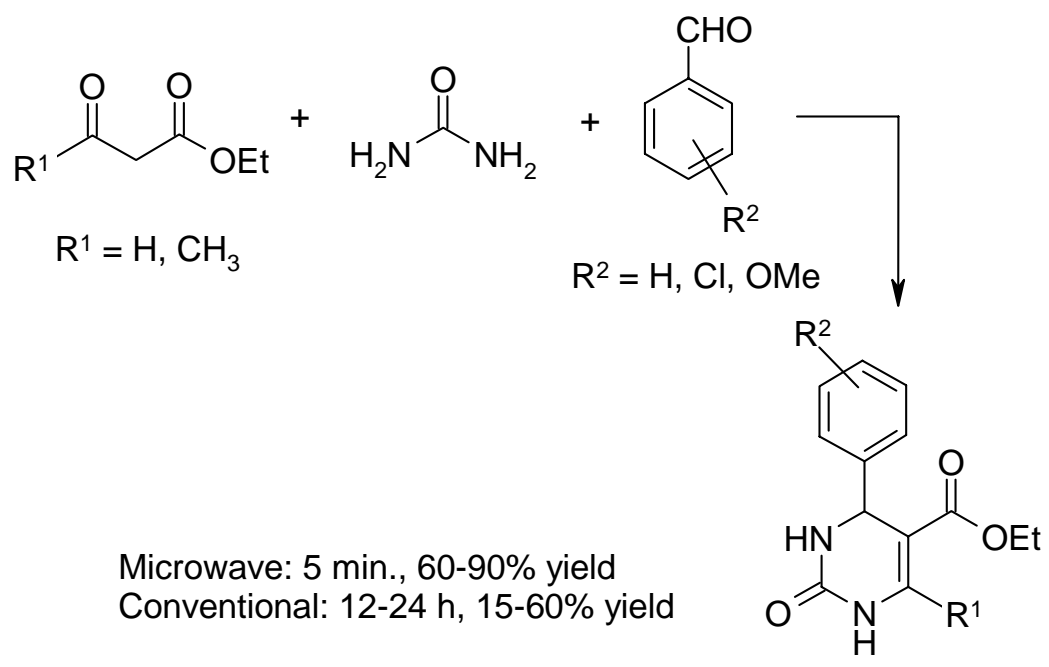

\section{Scheme 14}

\subsubsection{Tetrazines}

The Diels-Alder reaction between aza-olefins and aza-dicarboxylic ester to give tetrazines is speeded-up by a factor of 1000 by microwave enhancement as shown in Scheme $15 .{ }^{16}$

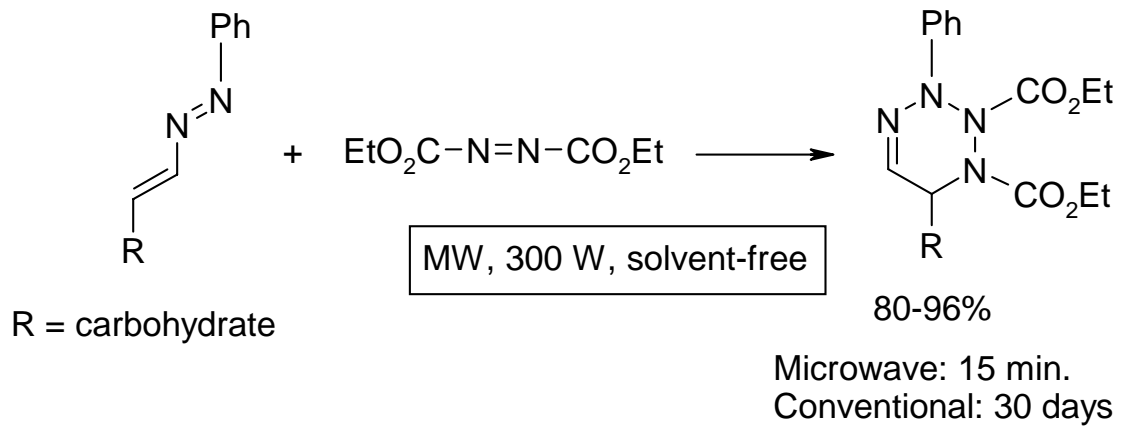

\section{Scheme 15}

\subsection{Polycyclic six-membered rings}

\subsubsection{Quinolines}

The Skraup synthesis has a bad reputation as it involves very messy conditions and gives only low yields of quinolines when carried out conventionally. Recently, it has been reported that microwave enhancement reduces the reaction time to a few minutes and allows high yields to be isolated (Scheme 16). ${ }^{17}$ 


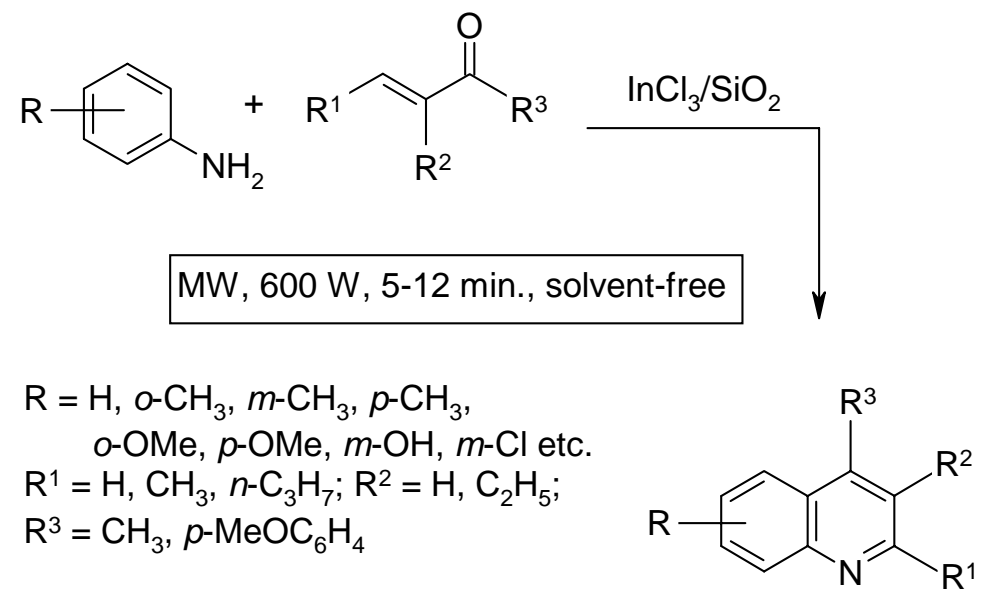

Microwave: $80-87 \%$

Conventional: $\mathrm{H}_{2} \mathrm{SO}_{4} / 150{ }^{\circ} \mathrm{C}$, low yields

\section{Scheme 16}

\subsubsection{Pyrimido[1,2-a]pyrimidines}

Pyrimido[1,2-a]pyrimidines are prepared from dihydroaminopyrimidines and chromone-3aldehydes as is shown in Scheme $17 .{ }^{18}$ Although the conventional reaction must proceed in refluxing ethanol, reactions are much faster and better yields have been obtained with microwaves.

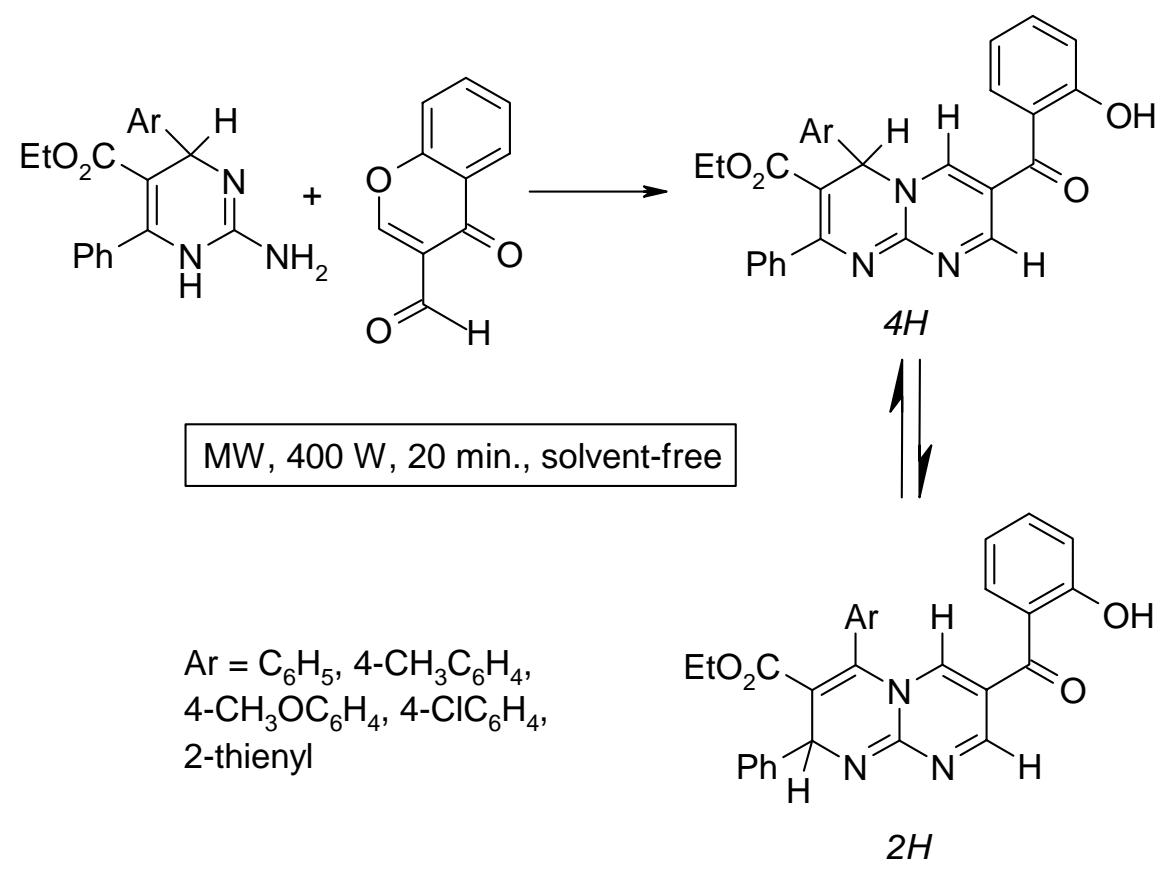

Microwave: 20 min., > 95\%

Conventional: EtOH reflux, 4 h, 60-70\%

\section{Scheme 17}


Until now we have concentrated on reactions in which heterocyclic rings are formed. However, microwave assistance can also be extremely valuable in many other types of reactions in heterocyclic chemistry.

\section{Nucleophilic Substitutions}

\subsection{Heterocyclic $\boldsymbol{C}$-alkylations}

Nucleophilic substitution reactions can be speeded-up very considerably as is illustrated in Scheme 18 for a chloro-naphthyridine derivative. ${ }^{3}$<smiles>CCOC(=O)c1cn(-c2ccc(F)cc2F)c2nc(Cl)c(F)cc2c1=O</smiles>

Microwave: $175^{\circ} \mathrm{C}, 10 \mathrm{~min} ., 100 \%$

Conventional: $100^{\circ} \mathrm{C}, 12-24 \mathrm{~h}, 35-60 \%$

\section{Scheme 18}

\subsection{Heterocyclic $\mathbf{N}$-alkylations}

Another class of nucleophilic substitution is involved in heterocyclic $N$-alkylation which we have illustrated in Scheme 19. This shows that nucleophilic substitution on the nitrogen atom of saccharin is significantly speeded-up by microwave irradiation. ${ }^{19}$ 


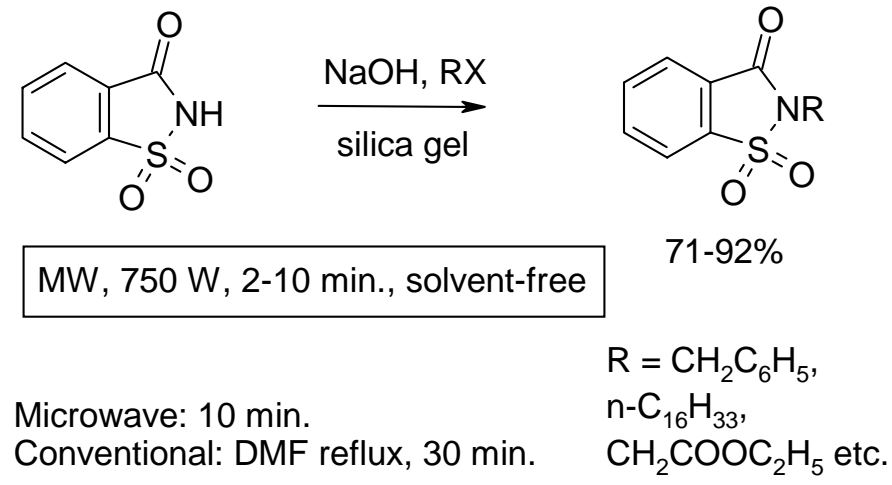

\section{Scheme 19}

\subsection{Selective-alkylation}

In Scheme 20, the results presented indicate that selectivity is achieved in the $N$-alkylation of 1,2,4-triazole under microwave conditions where only the $\mathrm{N}^{1}$-alkyl derivative was formed in contradistinction to the conventional conditions which give a considerable amount of the di-1,4substituted compound. ${ }^{20}$

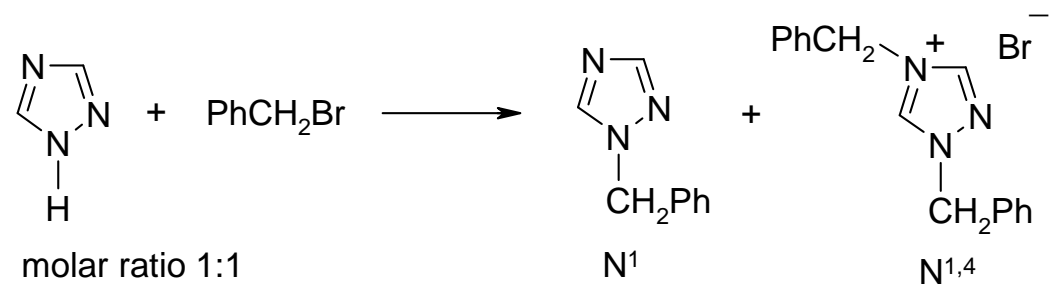

Microwave: $90-165^{\circ} \mathrm{C}, 1.5-5$ min., $70 \%$; only $\mathrm{N}^{1}$

Conventional: $14 \%$; only $\mathrm{N}^{1,4}$ isolated

\section{Scheme 20}

\subsection{Transition metal cross-coupling}

An important type of nucleophilic substitution reactions which are recently much exploited are comprised of transition metal cross-coupling. A Suzuki coupling is shown at the top of Scheme 21 to give significantly better yield in the presence of microwave irradiation. ${ }^{21 a}$ At the bottom of Scheme 21 another Suzuki coupling is speeded-up by a factor of $100 .^{21 b}$ 


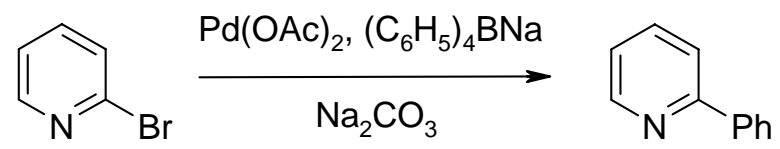

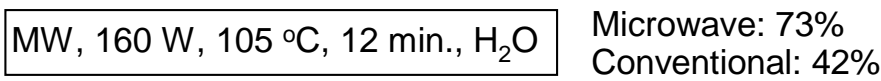

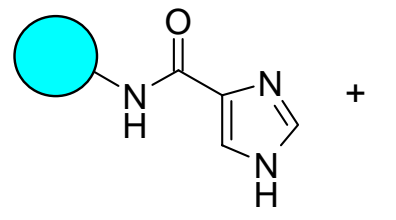<smiles>Cc1ccc(B(O)O)cc1</smiles>

1) $\mathrm{Cu}(\mathrm{OAc})_{2}$,

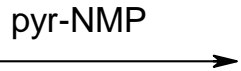

2) TFA

Microwave: $30 \mathrm{sec}$. Conventional: $48 \mathrm{~h}$<smiles>Cc1ccc(-n2cnc(C(N)=O)c2)cc1</smiles>

$60 \%$

\section{Scheme 21}

\section{Hetero-Diels-Alder reactions}

\subsection{Intramolecular reactions}

We have already seen one example of a hetero-Diels-Alder reaction involving acyclic components. Hetero-Diels-Alder reactions involving cyclic components which lead to polycyclic ring systems are of great importance. An intramolecular example shown in Scheme 22 indicates that the reaction was accelerated by a factor of around 1000 by microwave irradiation. ${ }^{22}$

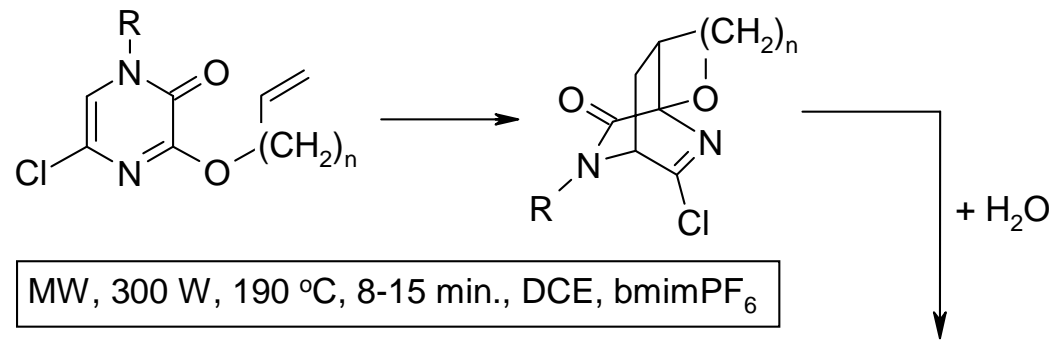

$$
\mathrm{MW}, 300 \mathrm{~W}, 130^{\circ} \mathrm{C}, 5 \mathrm{~min} .
$$

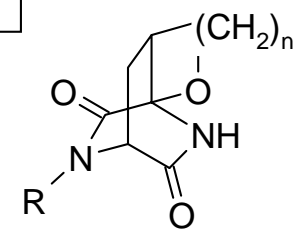

Microwave: $13-20$ min

Conventional: $\mathrm{PhCl}$ reflux, 2-3 days
$57-77 \%$

$\mathrm{R}=\mathrm{Bn}, \mathrm{Ph} ; \mathrm{n}=2,3$

\section{Scheme 22}

\subsection{Intermolecular reactions}


Scheme 23 shows two impressive examples of rate enhancement for intermolecular heteroDiels-Alder reactions. ${ }^{22}$ In the first example on the top of Scheme 23 the initial reaction is followed by elimination thus involving the conversion of a pyrazine derivative into a pyridine. Perhaps more impressive is the lower example in Scheme 23 where an autoclave is required under conventional conditions but which can be dispensed with when microwave acceleration is utilized.
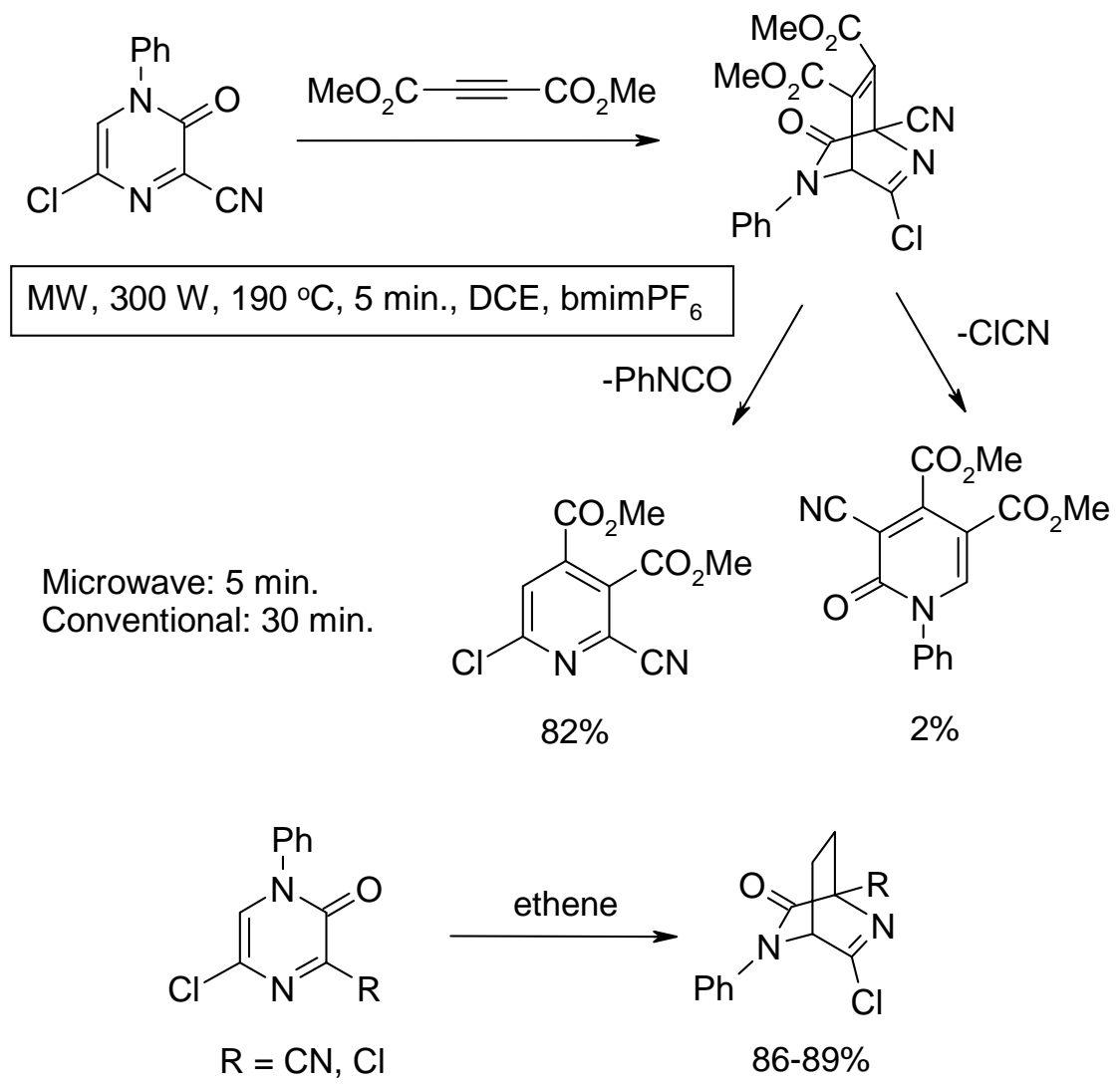

MW, $300 \mathrm{~W}, 190^{\circ} \mathrm{C}, 40-140 \mathrm{~min} ., \mathrm{DCB}$

Microwave: $40-140$ min.

Conventional: autoclave, 25 atm., $110^{\circ} \mathrm{C}, 12 \mathrm{~h}$

\section{Scheme 23}

\section{1,3-Dipolar cycloaddition reactions}

\subsection{Synthesis of $C$-carbamoyl-1,2,3-triazoles}

We now turn to some of our own recent work which has involved microwave induced 1,3dipolar cycloaddition of organic azides to acetylenic amides. As shown in Scheme 24 we were able to achieve these reactions under microwave conditions in a reasonable time at temperatures of around $70 \pm 15{ }^{\circ} \mathrm{C} .{ }^{23}$ Under conventional conditions the times were roughly 100 times as long and the temperature had to be taken up to $120{ }^{\circ} \mathrm{C}$. ${ }^{24}$ 


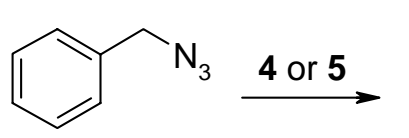

1

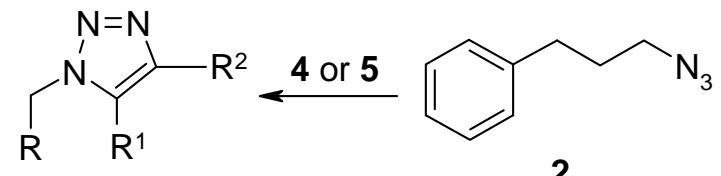

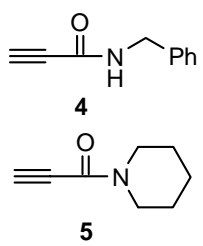

7-12

2

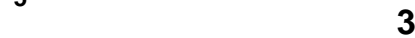

\begin{tabular}{lcccc}
\hline & $\mathrm{R}$ & $\mathrm{R}^{1}$ & $\mathrm{R}^{2}$ & $\mathrm{Y}(\%)^{\mathrm{a}}$ \\
\hline $\mathbf{7}$ & $\mathrm{Ph}$ & $\mathrm{H}$ & $\mathrm{CONHCH}_{2} \mathrm{Ph}$ & 65 \\
$\mathbf{8}$ & $\mathrm{Ph}$ & $\mathrm{H}$ & COpiperidinyl $^{2}$ & 63 \\
$\mathbf{9}$ & $\mathrm{Ph}\left(\mathrm{CH}_{2}\right)_{2}$ & $\mathrm{H}$ & CONHCH$_{2} \mathrm{Ph}$ & 62 \\
$\mathbf{1 0}$ & $\mathrm{Ph}\left(\mathrm{CH}_{2}\right)_{2}$ & $\mathrm{H}$ & COpiperidinyl $^{2}$ & 65 \\
$\mathbf{1 1}$ & $\mathrm{C}\left(\mathrm{CH}_{3}\right)\left(\mathrm{CH}_{2} \mathrm{OCH}_{2}\right)$ & $\mathrm{H}$ & CONHCH$_{2} \mathrm{Ph}$ & 84 \\
$\mathbf{1 2}$ & $\mathrm{C}\left(\mathrm{CH}_{3}\right)\left(\mathrm{CH}_{2} \mathrm{OCH}_{2}\right)$ & $\mathrm{H}$ & COpiperidinyl & 80 \\
\hline
\end{tabular}

${ }^{\mathrm{a}}$ Isolated yield of major regioisomer.

\section{Scheme 24}

\subsection{Synthesis of substituted mono-triazoles}

Scheme 25 shows some similar results of rate enhancements of formation of mono-triazoles from alkoxycarbonyl-activated acetylenes and azides. ${ }^{25}$

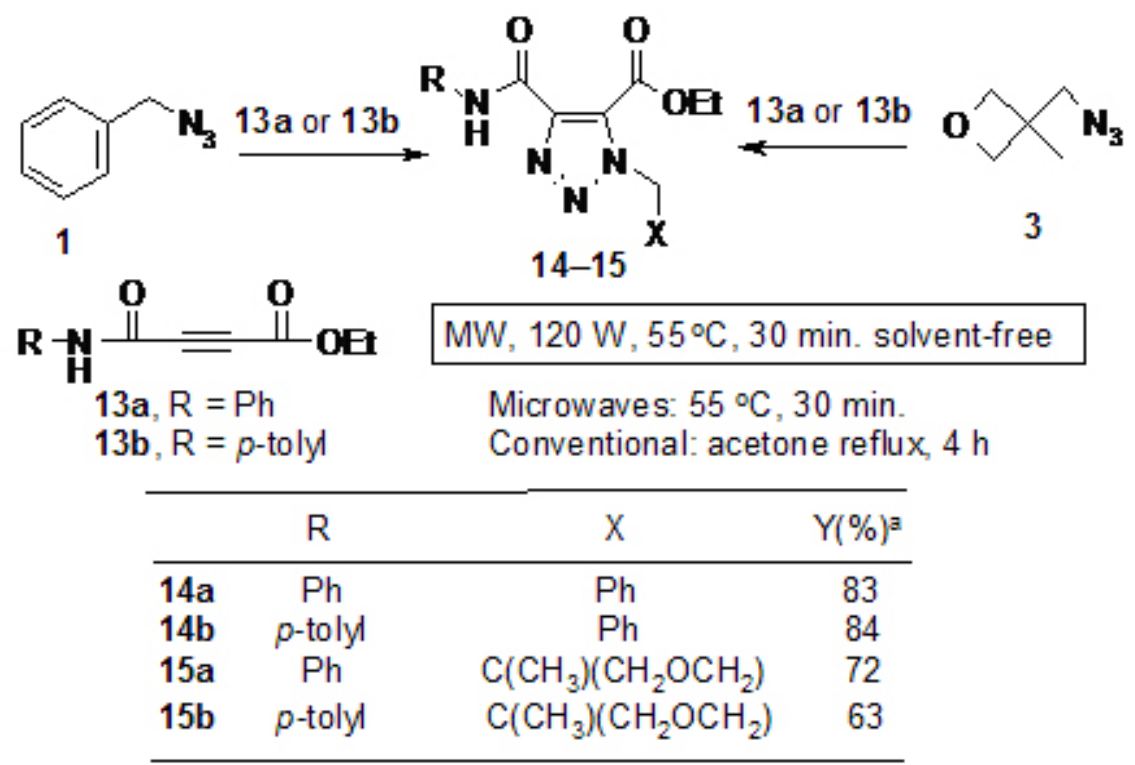

${ }^{\mathrm{a}}$ Isolated yield of major regioisomer. 


\section{Scheme 25}

\subsection{Synthesis of substituted bis-triazoles}

In Scheme 26 examples are shown of the preparation of bis-triazoles from mono-azides and bisamidopropiolates. In Scheme 27 we were able to make bis-triazoles from di-azide and monoamidopropiolates. $^{25}$ This should be appropriate for the preparation of polymers utilizing bistriazoles and bis-amidopropiolates.
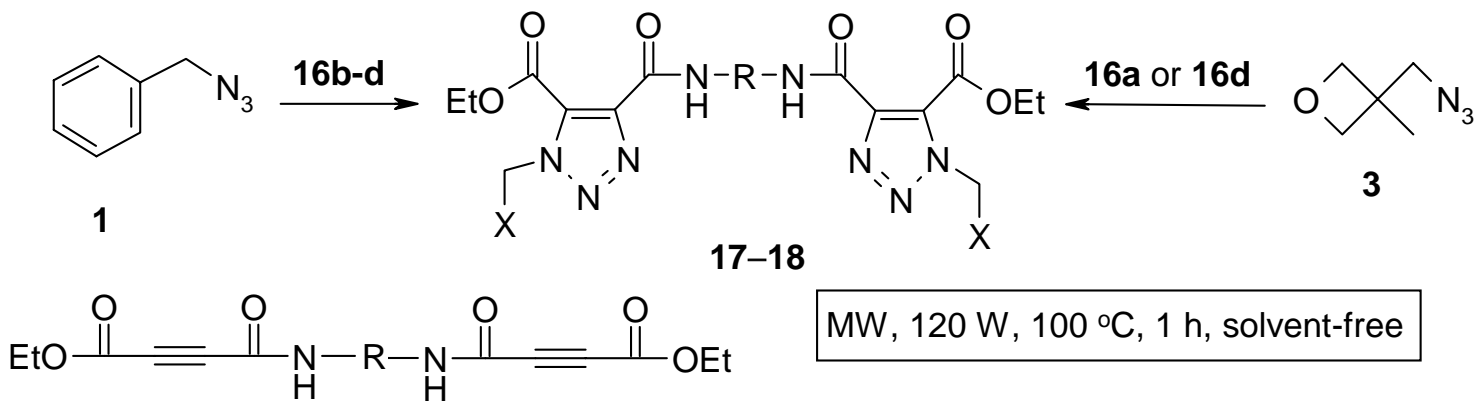

16a, $\mathrm{R}=p-\mathrm{C}_{6} \mathrm{H}_{4} ; \mathbf{1 6 b}, \mathrm{R}=$ tolylene-2,4;

16c, $\mathrm{R}=n-\mathrm{C}_{6} \mathrm{H}_{12} ; 16 \mathrm{~d}, \mathrm{R}=4,4^{\prime}-\mathrm{C}_{6} \mathrm{H}_{4} \mathrm{CH}_{2} \mathrm{C}_{6} \mathrm{H}_{4}$

\begin{tabular}{lccc}
\hline & $\mathrm{R}$ & $\mathrm{X}$ & $\mathrm{Y}(\%)^{\mathrm{a}}$ \\
\hline 17b & tolylene-2,4 & $\mathrm{Ph}$ & 41 \\
17c & $n-\mathrm{C}_{6} \mathrm{H}_{12}$ & $\mathrm{Ph}$ & 37 \\
17d & $4,4^{\prime}-\mathrm{C}_{6} \mathrm{H}_{4} \mathrm{CH}_{2} \mathrm{C}_{6} \mathrm{H}_{4}$ & $\mathrm{Ph}$ & 73 \\
18a & $p-\mathrm{C}_{6} \mathrm{H}_{4}$ & $\mathrm{C}\left(\mathrm{CH}_{3}\right)\left(\mathrm{CH}_{2} \mathrm{OCH}_{2}\right)$ & 43 \\
18d & $4,4^{\prime}-\mathrm{C}_{6} \mathrm{H}_{4} \mathrm{CH}_{2} \mathrm{C}_{6} \mathrm{H}_{4}$ & $\mathrm{C}\left(\mathrm{CH}_{3}\right)\left(\mathrm{CH}_{2} \mathrm{OCH}_{2}\right)$ & 42 \\
\hline
\end{tabular}

${ }^{\mathrm{a}}$ Isolated yield of major regioisomer.

\section{Scheme 26}

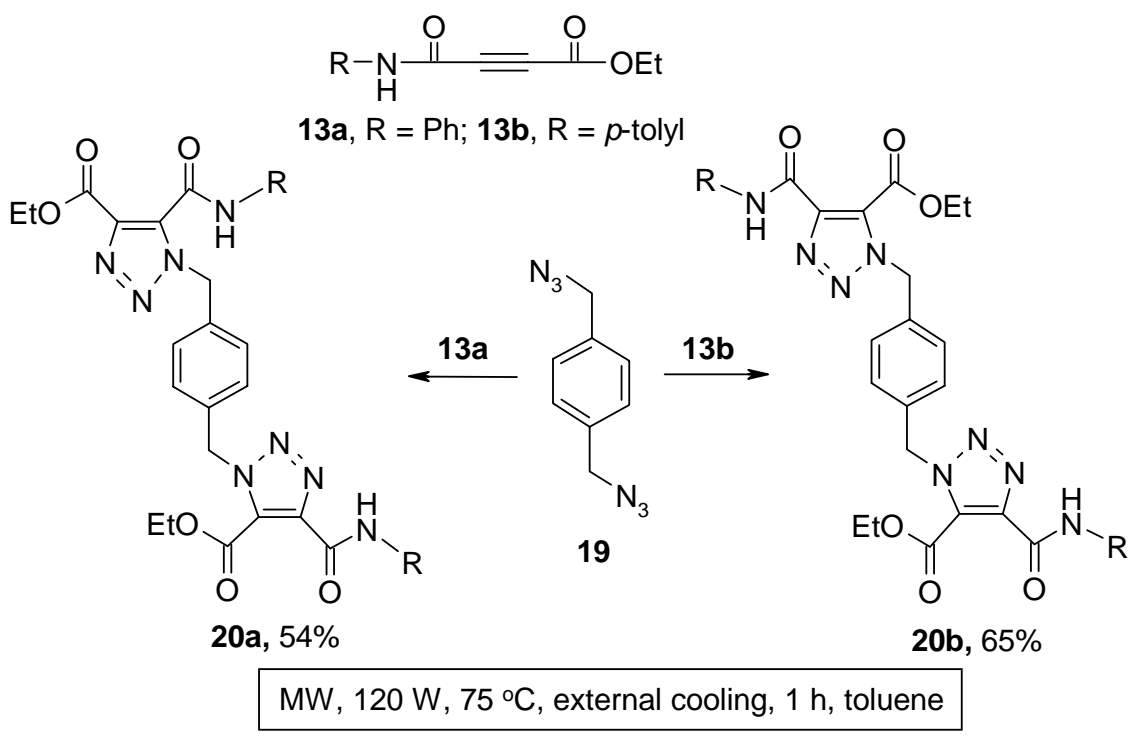




\section{Scheme 27}

\section{5. $\mathrm{N}$-Chlorination of amides}

Very recently, we have been able to show that $N$-chlorination can be carried out under very mild conditions and in high yields utilizing 1-chlorobenzotriazole (Scheme 28). ${ }^{25}$ Conventional methods for $\mathrm{N}$-chlorination generally involve reaction with tert-butyl hypochlorite in methanol for 2 h. $^{26}$

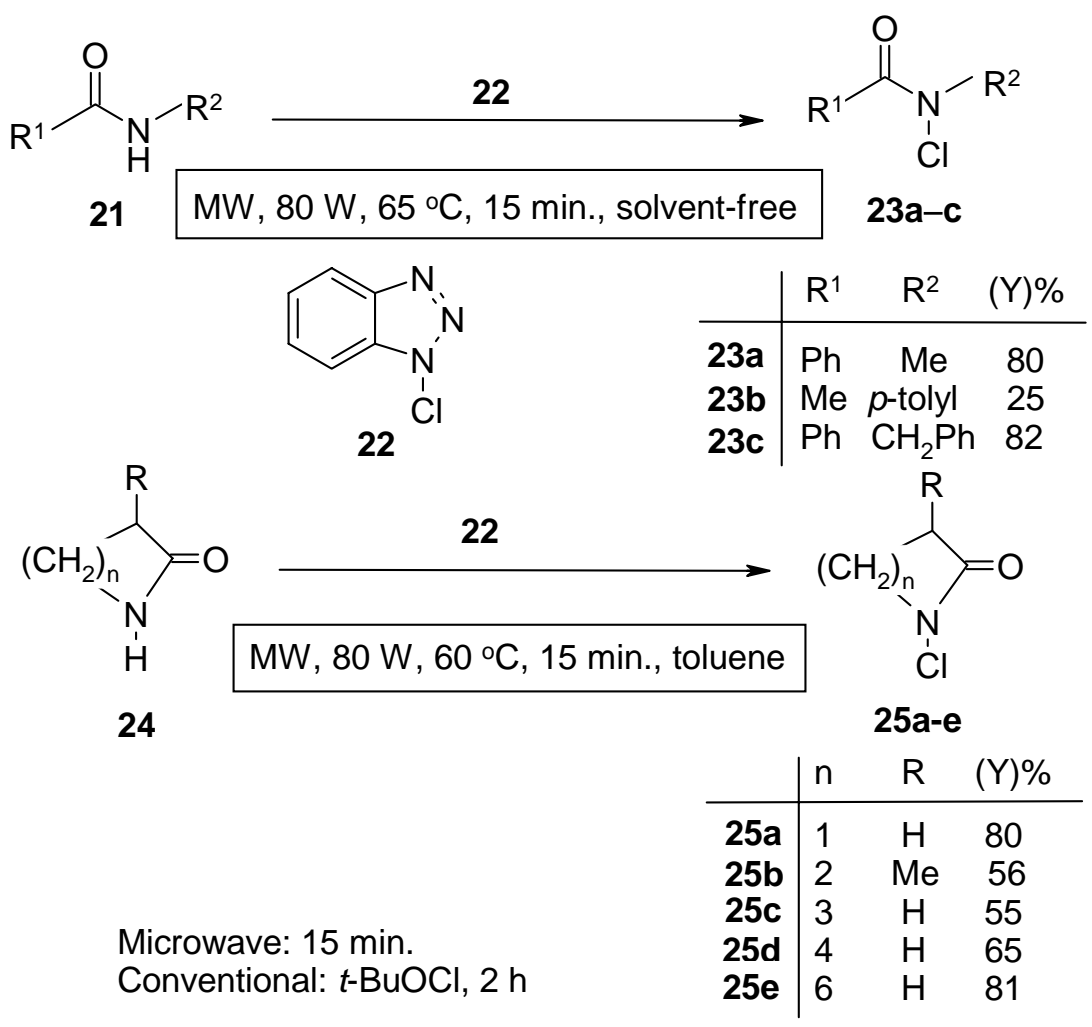

\section{Scheme 28}

In conclusion, we have summarized the recent applications of microwave activation in the synthesis and reactions of heterocycles. In comparison to conventional methods, microwave heating offers advantages such as reduced reaction times and temperatures, better yields, selectivity and reproducibility especially due to the advent of single-mode technology.

\section{Acknowledgments}

Financial support for this work from the Office of Naval Research under Grant No. 166626712 is gratefully acknowledged. We thank Dr. Clifford D. Bedford (Office of Naval Research, VA), Dr. David A. Ciaramitaro (Naval Air Weapons Station, CA) and Dr. Michael J. Collins (CEM, NC) 
for very helpful discussions and the CEM Corporation for providing the Discover ${ }^{\circledR}$ microwave synthesizer.

\section{References and Notes}

1. (a) Caddick, S. Tetrahedron 1995, 51, 10403. (b) Perreux, L.; Loupy, A. Tetrahedron 2001, 57, 9199. (c) Lidström, P.; Tierney, J.; Wathey, B.; Westman, J. Tetrahedron 2001, 57, 9225. (d) Larhed, M.; Hallberg, A. Drug Discovery Today 2001, 6, 406. (e) Fini, A.; Breccia, A. Pure Appl. Chem. 1999, 71, 573.

2. (a) Loupy, A.; Petit, A.; Hamelin, J.; Texier-Boullet, F.; Jacquault, P.; Mathé, D. Synthesis 1998, 1213. (b) Varma, R. S Green Chem. 1999, 1, 43. (c) Kuhnert, N.; Danks, T. N. Green Chem. 2001, 3, 68. (d) Tanaka, K.; Toda, F. Chem. Rev. 2000, 100, 1025.

3. Single-mode cavities offer more consistent and predictable energy distribution. Singlemode instruments produce one homogeneous, intense pocket of energy that is highly reproducible. Due to their uniform energy distribution and higher power density, these systems typically couple more efficiently with small samples. Hayes, B. L. Microwave Synthesis: Chemistry at the Speed of Light; CEM Publishing: Matthews, NC, 2002.

4. $\quad$ Danks, T. N. Tetrahedron Lett. 1999, 40, 3957.

5. Selvi, S.; Perumal, P. T. J. Heterocycl. Chem. 2002, 39, 1129.

6. Usyatinsky, A. Ya.; Khmelnitsky, Y. L. Tetrahedron Lett. 2000, 41, 5031.

7. Marrero-Terrero, A. L.; Loupy, A. Synlett 1996, 245.

8. Bentiss, F.; Lagrenée, M.; Barbry, D. Tetrahedron Lett. 2000, 41, 1539.

9. Alterman, M.; Hallberg, A. J. Org. Chem. 2000, 65, 7984.

10. Kaddar, H.; Hamelin, J.; Benhaoua, H. J. Chem. Res.(S) 1999, 718.

11. (a) Chandra Sheker Reddy, A.; Shanthan Rao, P.; Venkataratnam, R. V. Tetrahedron 1997, 53, 5847. (b) Narsaiah, B.; Sivaprasad, A.; Venkataratnam, R. V. J. Fluorine Chem. 1994, 66, 47.

12. Sridar, V. Indian J. Chem. 1997, 36B, 86.

13. Molina, A.; Vaquero, J. J.; Garcia-Navio, J. L.; Alvarez-Builla, J. Tetrahedron Lett. 1993, 34, 2673.

14. Öhberg, L.; Westman, J. Synlett 2001, 1296.

15. Quiroga, J.; Cisneros, C.; Insuasty, B.; Abonia, R.; Nogueras, M.; Sánchez, A. Tetrahedron Lett. 2001, 42, 5625.

16. Avalos, M.; Babiano, R.; Cintas, P.; Clemente, F. R.; Jimenez, J. L.; Palacios, J. C.; Sanchez, J. B. J. Org. Chem. 1999, 64, 6297.

17. Ranu, B. C.; Hajra, A.; Jana, U. Tetrahedron Lett. 2000, 41, 531.

18. Eynde, J. J. V.; Hecq, N.; Kataeva, O.; Kappe, C. O. Tetrahedron 2001, 57, 1785.

19. Ding, J.; Gu, H.; Wen, J.; Lin, C. Synth. Commun. 1994, 24, 301.

20. Abenhaïm, D.; Díez-Barra, E.; de la Hoz, A.; Loupy, A.; Sánchez-Migallón, A. Heterocycles 1994, 38, 793.

21. (a) Villemin, D.; Gómez-Escalonilla, M. J.; Saint-Clair, J.-F. Tetrahedron Lett. 2001, 42, 635. (b) Combs, A. P.; Saubern, S.; Rafalski, M.; Lam, P. Y. S. Tetrahedron Lett. 1999, 40, 1623. 
22. Van der Eycken, E.; Appukkuttan, P.; De Borggraeve, W.; Dehaen, W.; Dallinger, D.; Kappe, C. O. J. Org. Chem. 2002, 67, 7904.

23. Katritzky, A. R.; Singh, S. K. J. Org. Chem. 2002, 67, 9077.

24. (a) Häbich, D.; Barth, W.; Rösner, M. Heterocycles 1989, 29, 2083. (b) Mearman, R. C.; Newall, C. E.; Tonge, A. P. J. Antibiot. 1984, 37, 885. (c) Olesen, P. H.; Nielsen, F. E.; Pedersen, E. B.; Becher, J. J. Heterocycl. Chem. 1984, 21, 1603.

25. Unpublished results from authors' laboratory.

26. Johnson, R. A.; Greene, F. D. J. Org. Chem. 1975, 40, 2186. 